\title{
Variação da toxidez de Arrabidaea bilabiata (Bignoniaceae) em coelhos ${ }^{1}$
}

\author{
Flávia F. Jabour ${ }^{2 *}$, Josilene N. Seixas ${ }^{3}$, Carlos H. Tokarnia ${ }^{4}$ e Marilene F. Brito ${ }^{5}$
}

\begin{abstract}
Jabour F.F,, Seixas J.N., Tokarnia C.H. \& Brito M.F. 2006. [Variation of the toxicity of Arrabidaea bilabiata (Bignoniaceae) in rabbits.] Variação da toxidez de Arrabidaea bilabiata (Bignoniaceae) em coelhos. Pesquisa Veterinária Brasileira 26(3):171-176. Projeto Sanidade Animal Embrapa/UFRRJ, Km 47, Seropédica, RJ 23.890-000, Brazil. E-mail: flaviajabour@bol.com.br

The dried and powdered mature leaves and sprouts of Arrabidaea bilabiata (fam. Bignoniaceae), a liana or scandent shrub, were administered by stomach tube to 15 rabbits at doses of $0.25-6.0 \mathrm{~g} /$ $\mathrm{kg}$. The lowest dose of the sprouts collected in October (End of the dry season) causing death was $0.5 \mathrm{~g} / \mathrm{kg}$, whilst the lowest lethal dose of sprouts collected in May (End of the rainy season) was $1.0 \mathrm{~g} /$ $\mathrm{kg}$. With the mature leaves collected in October the lowest lethal dose was of $4.0 \mathrm{~g} / \mathrm{kg}$, and the lowest lethal dose of the mature leaves collected in May was $6.0 \mathrm{~g} / \mathrm{kg}$. The clinical course of the poisoning was peracute. The rabbits all of a sudden fell down with struggling movements, difficult and spaced breathing, and died. At necropsy, significant alterations were not observed and histopatological examination showed, as the more important changes, vacuolar hydropic degeneration of epithelial cells of the distal convoluted renal tubules, diffuse vacuolation of the cytoplasm and necrosis of hepatocytes, presence of eosinophilic sphaerules in the sinusoids, groups of heart muscle fibers with increased eosinophilia, besides congestion in the kidneys, liver, heart and lungs. It was concluded that the toxicity of $A$. bilabiata varies according to the season of the year and the growth stage of the plant. The plant was most toxic in October and the sprouts were more toxic than the mature leaves, confirming the data previously obtained in experiments with cattle and buffalos.
\end{abstract}

INDEX TERMS: Poisonous plants, Arrabidaea bilabiata, Bignoniaceae, plant poisoning, rabbit, pathology.

RESUMO.- A brotação e as folhas maduras dessecadas e trituradas de Arrabidaea bilabiata, um cipó ou arbusto escandente da família Bignoniaceae, foram administradas em suspensão aquosa por via intragástrica a 15 coelhos adultos nas doses que variaram de 0,25$6,0 \mathrm{~g} / \mathrm{kg}$. Nos experimentos com a brotação coletada em outubro (fim da época de seca), a menor dose que causou a morte dos coelhos foi de $0,5 \mathrm{~g} / \mathrm{kg}$ e em maio (fim da época de cheia), a menor dose que causou a morte foi de $1,0 \mathrm{~g} / \mathrm{kg}$. Já com as folhas maduras coletadas em outubro a menor dose que causou a morte dos

\footnotetext{
${ }^{1}$ Recebido em 15 de fevereiro de 2006. Aceito para publicação em 21 de fevereiro de 2006.

${ }^{2}$ Parte da dissertação de mestrado do primeiro autor no curso de Medicina Veterinária da Universidade Federal Rural do Rio de Janeiro (UFRRJ). Autor para correspondência: flaviajabour@bol.com.br

${ }^{3}$ Doutoranda do curso de Ciências Veterinárias da UFRRJ.

${ }^{4}$ Depto Nutrição Animal e Pastagem, Instituto de Zootecnia, UFRRJ , Seropédica, RJ 23835-000.

${ }^{5}$ Disciplina de Anatomia Patológica, Depto Epidemiologia e Saúde Pública, Instituto de Veterinária, UFRRJ.
}

coelhos foi de $4,0 \mathrm{~g} / \mathrm{kg}$ e em maio, a menor dose que causou a morte foi de $6,0 \mathrm{~g} / \mathrm{kg}$. A evolução em todos os casos letais foi superaguda. Clinicamente os coelhos de súbito debatiam-se com força na gaiola, caiam em decúbito lateral ou esternal, faziam movimentos de pedalagem, apresentavam acentuada dispnéia e morriam. À necropsia não foram observadas alterações significativas e ao exame histopatológico as lesões mais importantes caracterizaram-se, nos rins, por degeneração hidrópico-vacuolar das células epiteliais dos túbulos contornados distais, no fígado por vacuolização difusa do citoplasma e necrose de hepatócitos, predominantemente centro-lobular e paracentral e presença de esférulas eosinofílicas nos sinusóides hepáticos, no coração, por grupos de fibras cardíacas com eosinofilia aumentada, além de congestão nos rins, fígado, coração e pulmão. Neste estudo ficou estabelecido que a toxidez de $A$. bilabiata varia de acordo com a época do ano e o estado de maturação, pois essa planta foi mais tóxica em outubro e quando em brotação, confirmando, assim, os dados obtidos previamente em bovinos e búfalos.

TERMOS DE INDEXAÇÃO: Plantas tóxicas, Arrabidaea bilabiata, Bignoniaceae, intoxicação por planta, coelhos, patologia. 


\section{INTRODUÇÃO}

A família Bignoniaceae compreende cerca de 120 gêneros e 800 espécies (Poser et al. 2000) de plantas arbustivas, arbóreas e trepadeiras, distribuídas nas regiões tropicais da América do Sul e África. O gênero Arrabidaea ocorre na América tropical, do sul do México ao Brasil central (Costa \& Lima 1989) e inclui algumas espécies tóxicas para bovinos, dentre as quais se destaca Arrabidaea bilabiata (Fig.1-3), conhecida pelos nomes populares de "chibata" ou "gibata", classificada no grupo das que causam "morte súbita". Depois de Palicourea marcgravi (Tokarnia et al. 2000), A. bilabiata é a planta mais importante como causa de morte em bovinos na região Amazônica. Seu habitat são as várzeas (Fig.1) (Döbereiner et al. 1983). De ambas as plantas foi isolado o princípio tóxico ácido monofluoracético (Oliveira 1963, Krebs et al. 1994).

Existem vários fatores que podem influenciar na toxidez das plantas como estado de maturação (brotação, folha madura), procedência e época do ano (épocas de chuva e de seca). Nos experimentos realizados por Döbereiner et al. (1983) com A. bilabiata em bovinos houve grande variação na toxidez da planta, no entanto,

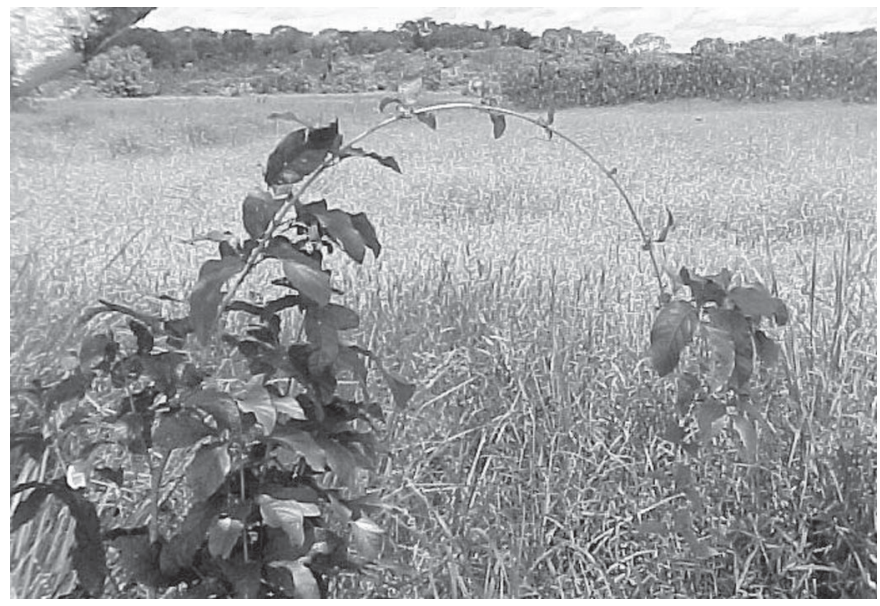

Fig.1. Crescimento de Arrabidaea bilabiata sob a forma de cipó escandente, no município de Inhangapi, Pará.

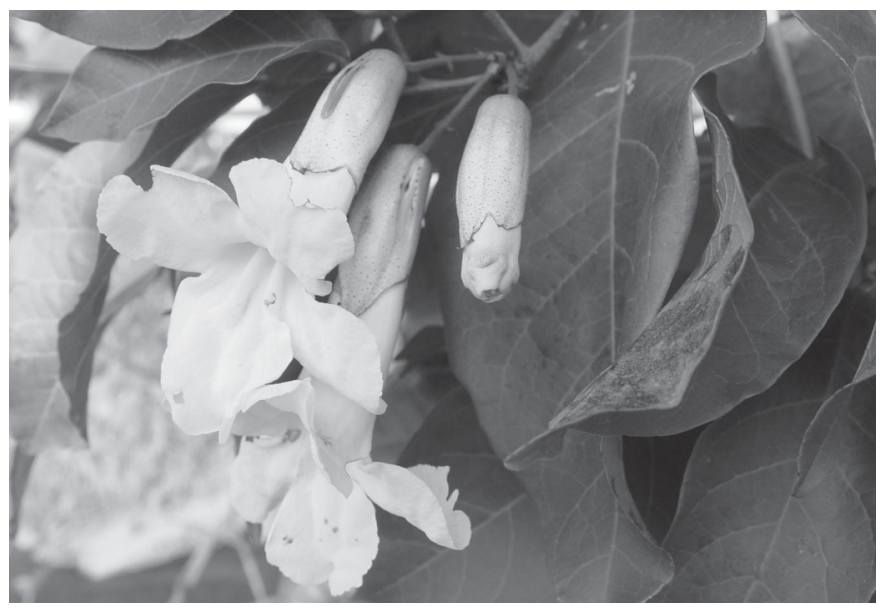

Fig.2. Inflorescência de Arrabidaea bilabiata (Sprague) Sandw.

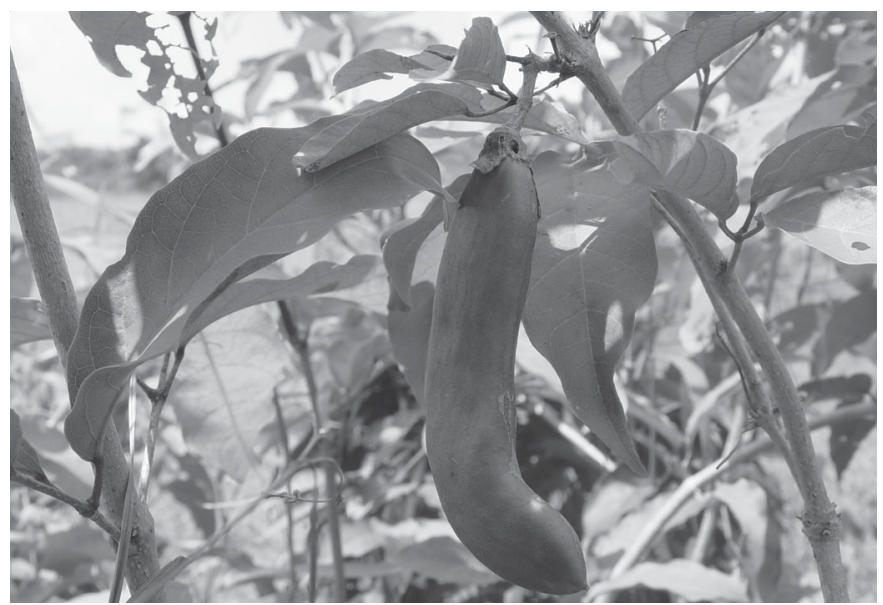

Fig.3. Frutificação de Arrabidaea bilabiata sob a forma de cápsula.

não foi possível verificar quais os fatores responsáveis por essa variação devido ao número insuficiente de experimentos comparativos realizados (brotação/folhas tenras versus folhas maduras, época do ano em que foi coletada a planta e procedência da mesma). Experimentos realizados em coelhos por Döbereiner et al. (1984), sugerem que a brotação é mais tóxica que as folhas maduras e que a procedência da planta tem influência no grau de toxidez de $A$. bilabiata. Todos os experimentos em coelhos foram realizados com a planta sempre coletada apenas na época de cheia do rio Amazonas, não sendo possível verificar uma eventual variação da toxidez da planta de acordo com a época do ano. Já nos experimentos realizados em búfalos por Tokarnia et al. (2004), foram administradas brotação e folhas maduras da A. bilabiata, coletadas de um mesmo local e em maio (fim da época de cheia) e outubro (fim da época de seca). Nestes animais, chegou-se à conclusão de que, em outubro a planta é mais tóxica do que em maio e que, em ambas as épocas do ano, a brotação é mais tóxica do que as folhas maduras.

Este trabalho tem por objetivo continuar os estudos sobre a toxidez de A. bilabiata, realizando-se experimentos com folhas maduras e brotação, coletadas no mesmo local e nas mesmas épocas de cheia e de seca que nos experimentos com búfalos realizados por Tokarnia et al. (2004), utilizando-se o coelho, por ser esta espécie comprovadamente sensível à intoxicação por esta planta.

\section{MATERIAL E MÉTODOS}

A brotação e as folhas maduras de Arrabidaea bilabiata foram colhidas no município de Inhangapi, Pará, em outubro de 2002 e 2003 e em maio de 2004 e colocadas separadamente em sacos de algodão. As folhas foram dessecadas à temperatura ambiente e à sombra, trituradas em moinho Wiley com malha 60, acondicionadas em vidros hermeticamente fechados e guardadas também à temperatura ambiente e à sombra.

Foram utilizados 18 coelhos adultos, da raça Nova Zelândia, com pesos entre $2.820 \mathrm{~g}$ e $4.050 \mathrm{~g}$, dos quais 15 receberam a planta e 3 serviram como controle. Os coelhos foram mantidos em gaiolas individuais e ficaram em jejum por um dia antes da administração da planta.

As folhas foram administradas sob forma de pó suspenso em 
água por via intragástrica, por meio de uma sonda, conforme técnica descrita por Döbereiner et al. (1976) e modificada.

Após a administração os coelhos foram observados continuamente durante as $\mathbf{2 4}$ horas seguintes, e passado esse período, em intervalos regulares de 2 horas até completar 48 horas da última administração. Água e ração foram oferecidos mais ou menos 4 horas após a administração da planta.

Os coelhos foram necropsiados imediatamente após a morte e fragmentos de todos os órgãos foram coletados e fixados em formol a $10 \%$. Após o processamento de rotina, foram preparados cortes histológicos em espessura de $5 \mu$ e corados pela hematoxilina-eosina (HE).

\section{RESULTADOS}

Nos experimentos realizados verificou-se que dos 15 coelhos que receberam Arrabidaea bilabiata, 8 morreram. A evolução em todos os casos letais foi superaguda.

Nos experimentos com a brotação coletada em outubro, a menor dose que causou a morte dos coelhos foi de $0,5 \mathrm{~g} / \mathrm{kg}$ (Coelho 1400). O início dos sintomas após a administração da planta nos coelhos que morreram, variou de $2 \mathrm{~h} 12 \mathrm{~min}$ a 16 horas (Quadro 1). Em maio, a menor dose que causou a morte foi de $1,0 \mathrm{~g} / \mathrm{kg}$ (Coelho 1405) e o início dos sintomas após a administração da planta foi de 10h20min (Quadro 2).

Já com as folhas maduras coletadas em outubro a menor dose que causou a morte dos coelhos foi de $4,0 \mathrm{~g} / \mathrm{kg}$ (Coelho 1399). O início dos sintomas após a administração da planta foi de 9 h10min e $10 \mathrm{~h}$ (Quadro 3). Em, a menor dose que causou a morte foi de $6,0 \mathrm{~g} / \mathrm{kg}$ (Coelho 1417). O início dos sintomas após a administração da planta foi de $12 \mathrm{~h} 56 \mathrm{~min}$ (Quadro 4).

Clinicamente os coelhos, em sua maioria, de súbito debatiam-se fortemente, caiam em decúbito lateral ou esternal, faziam movimentos de pedalagem, apresentavam acentuada dispnéia e morriam. A evolução variou de 1-3 minutos, com exceção de dois coelhos ( $\mathrm{n}^{\circ} 1391$ e 1399), em que a evolução foi de 39 minutos e 1 hora, respectivamente.

À necropsia verificaram-se fígado com congestão nos Coelhos 1391, 1397 e 1405 e lobulação evidente nos Coelhos 1394, 1397, 1400, 1399 e 1419, rins congestos nos coelhos 1397, 1417 e 1405, coração com hipertrofia do ventrículo esquerdo no Coelho 1417 e dilatação bem evidente do átrio e ventrículo direito no Coelho 1399, pulmão com a superfície vítrea e congesta no Coelho 1399.

Os exames histopatógicos (Quadro 5) revelaram no fígado congestão em todos os animais, leucocitoestase, predominantemente polimorfonuclear, nos Coelhos 1391, 1394, 1400 e 1419, moderada a acentuada vacuolização macro e microvesicular no citoplasma dos hepatócitos tendendo a ser difusa (Fig.4), porém mais pronunciada nas zonas intermediária, e na região centrolobular nos Coelhos 1391, 1394, 1400, 1399 e 1419; por vezes o citoplasma apresentava-se com um aspecto granular e/ ou espumoso. Observaram-se ainda focos com tumefação de hepatócitos nos Coelhos 1391, 1419 e 1405, necrose dos hepatócitos caracterizada por núcleos picnóticos e em cariorrexia tendendo a localizar-se predominantemente nas regiões

Quadro 1. Principais dados sobre a intoxicação experimental em coelhos com a brotação de Arrabidaea bilabiata coletada em outubro de 2002 e 2003

\begin{tabular}{|c|c|c|c|c|c|c|c|c|}
\hline $\begin{array}{c}\text { Coelho } \mathrm{n}^{\circ} \\
\text { (Registro SAP) }\end{array}$ & $\begin{array}{l}\text { Peso } \\
(\mathrm{g})\end{array}$ & $\begin{array}{l}\text { Data da } \\
\text { coleta }\end{array}$ & $\begin{array}{l}\text { Data e hora da } \\
\text { administração }\end{array}$ & $\begin{array}{l}\text { Dose } \\
(\mathrm{g} / \mathrm{kg})\end{array}$ & $\begin{array}{l}\text { Dose total } \\
\text { (g) ingerida }\end{array}$ & $\begin{array}{c}\text { Início dos } \\
\text { sintomas após } \\
\text { administração }\end{array}$ & Evolução & Desfecho \\
\hline $\begin{array}{c}1391 \\
(29594)\end{array}$ & 3.490 & $\begin{array}{c}\text { Outubro } \\
2002\end{array}$ & $\begin{array}{c}10.04 .03 \\
9: 08\end{array}$ & 2,0 & 7,0 & $2 \mathrm{~h} 12 \mathrm{~min}$ & $39 \mathrm{~min}$ & Morreu \\
\hline $\begin{array}{c}1394 \\
(29602)\end{array}$ & 3.140 & $\begin{array}{c}\text { Outubro } \\
2002\end{array}$ & $\begin{array}{c}16.04 .03 \\
9: 04\end{array}$ & 1,0 & 3,2 & $5 \mathrm{~h} 10 \mathrm{~min}$ & $2 \min$ & Morreu \\
\hline $\begin{array}{c}1400 \\
(29607)\end{array}$ & 2.820 & $\begin{array}{c}\text { Outubro } \\
2002\end{array}$ & $\begin{array}{c}26.04 .03 \\
9: 10\end{array}$ & 0,5 & 1,41 & $4 \mathrm{~h} 50 \mathrm{~min}$ & $3 \mathrm{~min}$ & Morreu \\
\hline 1409 & 3.300 & $\begin{array}{c}\text { Outubro } \\
2002\end{array}$ & $\begin{array}{c}17.07 .03 \\
9: 00\end{array}$ & 0,25 & 0,825 & - & - & Sem sintomas \\
\hline $\begin{array}{c}1397 \\
(29920)\end{array}$ & 2.940 & $\begin{array}{c}\text { Outubro } \\
2003\end{array}$ & $\begin{array}{c}15.11 .03 \\
9: 30\end{array}$ & 1,0 & 2,94 & $16 \mathrm{~h}$ & $3 \mathrm{~min}$ & Morreu \\
\hline 1421 & 2.920 & $\begin{array}{c}\text { Outubro } \\
2003\end{array}$ & $\begin{array}{c}18.11 .03 \\
14: 05\end{array}$ & 0,5 & 1,46 & - & - & Sem sintomas \\
\hline 1402 & 3.790 & & & & Controle & & & \\
\hline
\end{tabular}

Quadro 2. Principais dados sobre a intoxicação experimental em coelhos com a brotação de Arrabidaea bilabiata coletada em maio de 2004

\begin{tabular}{ccccccccc}
\hline $\begin{array}{c}\text { Coelho no } \\
(\text { Registro SAP) }\end{array}$ & $\begin{array}{c}\text { Peso } \\
(\mathrm{g})\end{array}$ & $\begin{array}{c}\text { Data da } \\
\text { coleta }\end{array}$ & $\begin{array}{c}\text { Data e hora da } \\
\text { administração }\end{array}$ & $\begin{array}{c}\text { Dose } \\
(\mathrm{g} / \mathrm{kg})\end{array}$ & $\begin{array}{c}\text { Dose total } \\
(\mathrm{g}) \text { ingerida } \\
(\text { dose única) }\end{array}$ & $\begin{array}{c}\text { Início dos } \\
\text { sintomas após } \\
\text { administração }\end{array}$ & Evolução & Desfecho \\
\hline 1405 & 3.480 & $\begin{array}{c}\text { Maio } \\
2004\end{array}$ & $\begin{array}{c}15 / 06 / 04 \\
15: 15\end{array}$ & 1,0 & 3,48 & 10 h 20 min & 1 min & Morreu \\
$(30274)$ & 3.800 & $\begin{array}{c}\text { Maio } \\
2004\end{array}$ & $\begin{array}{c}15 / 06 / 04 \\
15: 22\end{array}$ & 0,5 & 1,9 & - & Sem sintomas \\
1406 & 3.120 & & & Controle &
\end{tabular}


Quadro. 3. Principais dados sobre a intoxicação experimental em coelhos com as folhas maduras de Arrabidaea bilabiata coletadas em outubro de 2002 e 2003

\begin{tabular}{|c|c|c|c|c|c|c|c|c|c|}
\hline $\begin{array}{c}\text { Coelho } \mathrm{n}^{\mathrm{o}} \\
\text { (Registro SAP) }\end{array}$ & $\begin{array}{l}\text { Peso } \\
(\mathrm{g})\end{array}$ & $\begin{array}{l}\text { Data da } \\
\text { coleta }\end{array}$ & $\begin{array}{l}\text { Data e hora da } \\
\text { administração }\end{array}$ & $\begin{array}{l}\text { Dose } \\
(\mathrm{g} / \mathrm{kg})\end{array}$ & $\begin{array}{l}\text { Quantidade }(\mathrm{g}) \\
\text { da planta e } \mathrm{n}^{\circ} \text { de } \\
\text { administrações }\end{array}$ & $\begin{array}{l}\text { Dose total } \\
\text { (g) ingerida }\end{array}$ & $\begin{array}{c}\text { Início dos } \\
\text { sintomas após } \\
\text { administração }\end{array}$ & Evolução & Desfecho \\
\hline $\begin{array}{c}1392 \\
-\end{array}$ & 4.050 & $\begin{array}{c}\text { Outubro } \\
2002\end{array}$ & $\begin{array}{c}10.04 .03 \\
9: 10 \\
9: 25\end{array}$ & 2,0 & $\begin{array}{l}8,1 \\
\mathrm{x} 2\end{array}$ & 16,2 & - & - & Sem sintomas \\
\hline $\begin{array}{c}1393 \\
-\end{array}$ & 3.330 & $\begin{array}{c}\text { Outubro } \\
2002\end{array}$ & $\begin{array}{c}16.04 .03 \\
8: 50 \\
12: 25\end{array}$ & 4,0 & $\begin{array}{l}6,7 \\
\times 2\end{array}$ & 13,4 & - & - & Sem sintomas \\
\hline $\begin{array}{c}1399 \\
(29608)\end{array}$ & 3.680 & $\begin{array}{c}\text { Outubro } \\
2002\end{array}$ & $\begin{array}{c}26 / 04 / 03 \\
8: 50 \\
13: 00\end{array}$ & 4,0 & $\begin{array}{c}7,36 \\
x 2\end{array}$ & 14,72 & $9 \mathrm{~h} 10 \mathrm{~min}$ & 1 hora & Morreu \\
\hline $\begin{array}{c}1420 \\
-\end{array}$ & 2.980 & $\begin{array}{c}\text { Outubro } \\
2003\end{array}$ & $\begin{array}{c}18.11 .03 \\
13: 55 \\
19: 15\end{array}$ & 4,0 & $\begin{array}{l}6,0 \\
\times 2\end{array}$ & 12,0 & - & - & Sem sintomas \\
\hline $\begin{array}{c}1419 \\
(29919)\end{array}$ & 3.140 & $\begin{array}{c}\text { Outubro } \\
2003\end{array}$ & $\begin{array}{c}15.11 .03 \\
9: 25 \\
14: 15\end{array}$ & 6,0 & $\begin{array}{l}11,04 \\
\times 2\end{array}$ & 22,08 & $10 \mathrm{~h}$ & $2 \mathrm{~min}$ & Morreu \\
\hline
\end{tabular}

Quadro 4. Principais dados sobre a intoxicação experimental em coelhos com as folhas maduras de Arrabidaea bilabiata coletadas em maio de 2004

\begin{tabular}{|c|c|c|c|c|c|c|c|c|c|}
\hline $\begin{array}{c}\text { Coelho } \mathrm{n}^{\mathrm{o}} \\
\text { (Registro SAP) }\end{array}$ & $\begin{array}{l}\text { Peso } \\
(\mathrm{g})\end{array}$ & $\begin{array}{l}\text { Data da } \\
\text { coleta }\end{array}$ & $\begin{array}{l}\text { Data e hora da } \\
\text { administração }\end{array}$ & $\begin{array}{l}\text { Dose } \\
\text { (g/kg) }\end{array}$ & $\begin{array}{l}\text { Quantidade }(\mathrm{g}) \\
\text { da planta e } \mathrm{n}^{\circ} \text { de } \\
\text { administrações }\end{array}$ & $\begin{array}{l}\text { Dose total } \\
\text { (g) ingerida }\end{array}$ & $\begin{array}{c}\text { Início dos } \\
\text { sintomas após } \\
\text { administração }\end{array}$ & Evolução & Desfecho \\
\hline $\begin{array}{c}1417 \\
(30275)\end{array}$ & 3.400 & $\begin{array}{l}\text { Maio } \\
2004\end{array}$ & $\begin{array}{c}15.06 .04 \\
14: 53 \\
22: 00\end{array}$ & 6,0 & $\begin{array}{c}10,2 \\
\mathrm{x} 2\end{array}$ & 20,4 & 12 h 56 min & $1 \mathrm{~min}$ & Morreu \\
\hline $\begin{array}{c}1413 \\
-\end{array}$ & 3.620 & $\begin{array}{l}\text { Maio } \\
2004\end{array}$ & $\begin{array}{c}15.06 .04 \\
15: 03 \\
22: 05\end{array}$ & 4,0 & $\begin{array}{c}7,24 \\
\mathrm{x} 2\end{array}$ & 14,48 & - & - & Sem sintomas \\
\hline 1406 & 3.120 & & & & & Controle & & & \\
\hline
\end{tabular}

Quadro 5 . Achados histopatológicos observados na intoxicação experimental por Arrabidaea bilabiata em coelhos

\begin{tabular}{|c|c|c|c|c|c|c|c|c|c|c|c|c|}
\hline \multirow{2}{*}{$\begin{array}{c}\text { Coelho } n^{\circ} \\
\text { (reg SAP) }\end{array}$} & \multicolumn{6}{|c|}{ Figado } & \multicolumn{2}{|c|}{$\operatorname{Rim}$} & \multicolumn{2}{|c|}{ Coração } & \multicolumn{2}{|c|}{ Pulmão } \\
\hline & Congestão & $\begin{array}{l}\text { Leucocito- } \\
\text { estase }\end{array}$ & $\begin{array}{c}\text { Vacuolização } \\
\text { dos hepa- } \\
\text { tócitos }\end{array}$ & $\begin{array}{c}\text { Tumefação } \\
\text { de hepa- } \\
\text { tócitos }\end{array}$ & $\begin{array}{c}\text { Necrose } \\
\text { com figuras } \\
\text { de picnose e } \\
\text { cariorrexia }\end{array}$ & $\begin{array}{c}\text { Presença de } \\
\text { esférulas eo- } \\
\text { sinofílicas nos } \\
\text { sinusóides }\end{array}$ & Congestão & $\begin{array}{l}\text { Degeneração } \\
\text { hidrópico- } \\
\text { vacuolar das } \\
\text { células epite- } \\
\text { liais dos tú- } \\
\text { bulos contor- } \\
\text { nados distais }\end{array}$ & $\begin{array}{l}\text { Congestão } \\
- \\
-\end{array}$ & $\begin{array}{l}\text { Grupos de fi- } \\
\text { bras com tu- } \\
\text { mefação, per- } \\
\text { da da estria- } \\
\text { ção transver- } \\
\text { sal e aumento } \\
\text { da eosinofilia }\end{array}$ & Congestão & Edema \\
\hline $\begin{array}{c}1394 \\
(29602)\end{array}$ & + & ++ & $\begin{array}{c}++ \\
\mathrm{ZI} \mathrm{e} \mathrm{CL}\end{array}$ & - & - & - & $(+)$ & $(+)$ & - & - & $(+)$ & - \\
\hline $\begin{array}{c}1397 \\
(29920)\end{array}$ & ++ & - & $\begin{array}{c}+++ \\
\text { ZI }\end{array}$ & - & $\begin{array}{c}+++ \\
\text { CL e PC }\end{array}$ & + & - & - & - & + & $(+)$ & - \\
\hline $\begin{array}{c}1400 \\
(29.607)\end{array}$ & + & ++ & $\begin{array}{c}++ \\
\mathrm{ZI} \text { e CL}\end{array}$ & - & $\begin{array}{c}(+) \\
\text { CLe PC }\end{array}$ & - & - & + & - & + & +++ & - \\
\hline $\begin{array}{c}1405 \\
(30274)\end{array}$ & + & - & $\begin{array}{c}+++ \\
\text { ZI }\end{array}$ & + & - & - & $(+)$ & - & $(+)$ & - & $(+)$ & - \\
\hline
\end{tabular}

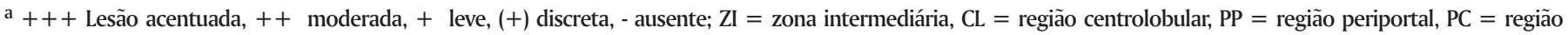
paracentral. 
4

Fig.4. Vacuolização macro e microvesicular difusa no citoplasma de hepatócitos, moderada leucocitoestase predominantemente polimorfonuclear e discreta congestão na intoxicação experimental por Arrabidaea bilabiata (Coelho 1419). HE, obj. 25.

Fig.5. Presença de esférula eosinofílica (seta) em sinusóide hepático na intoxicação experimental por Arrabidaea bilabiata (Coelho 1391). HE, obj. 100.

Fig.6. Vacuolização nas células epiteliais dos túbulos uriníferos contornados distais (setas) na intoxicação experimental por Arrabidaea bilabiata (Coelho 1419). HE, obj. 25.
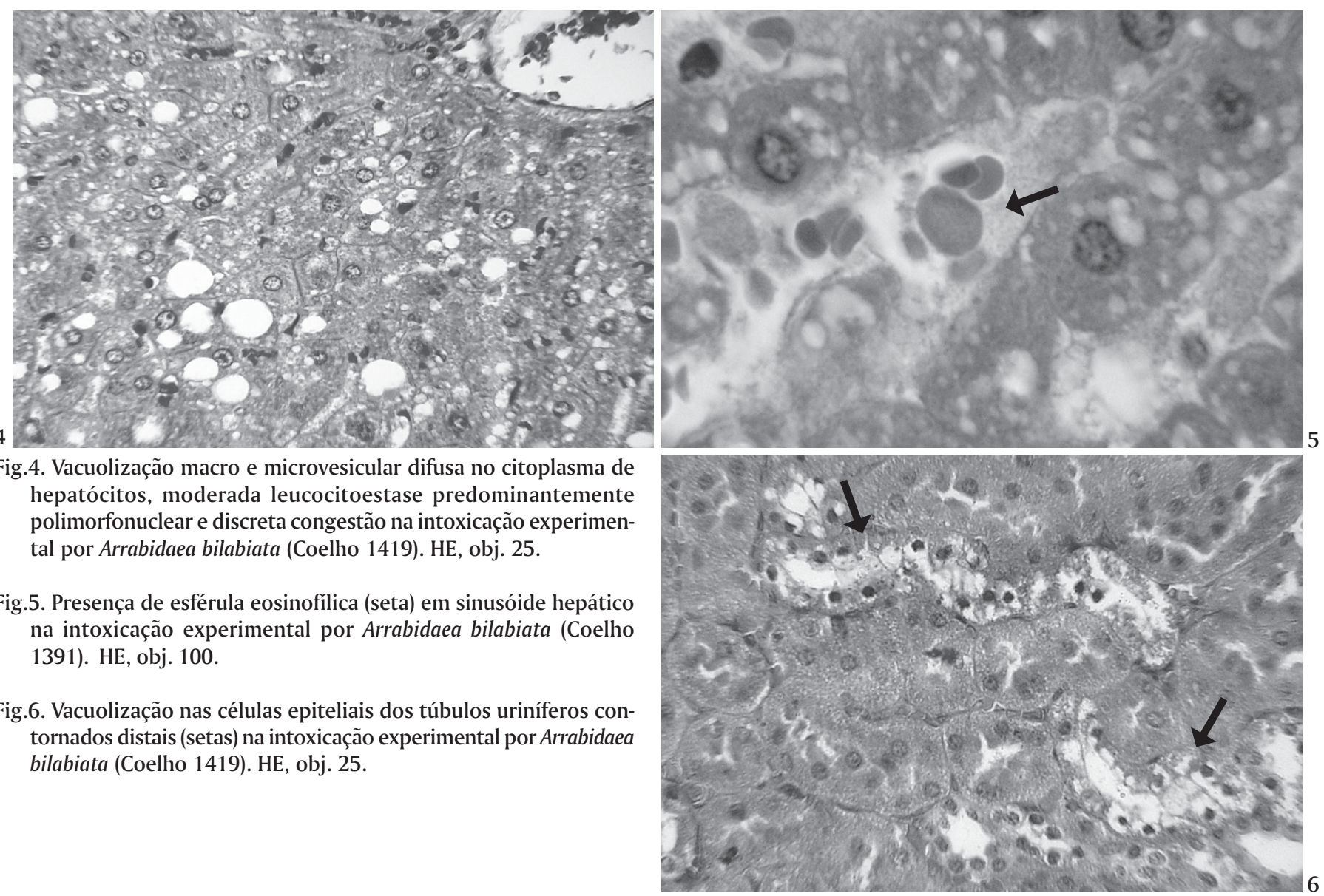

túbulos contornados distais (Fig.6) nos Coelhos 1394, 1400, 1419 e 1417; na maioria das vezes o citoplasma das células afetadas encontrava-se rarefeito e o núcleo picnótico. O coração apre-

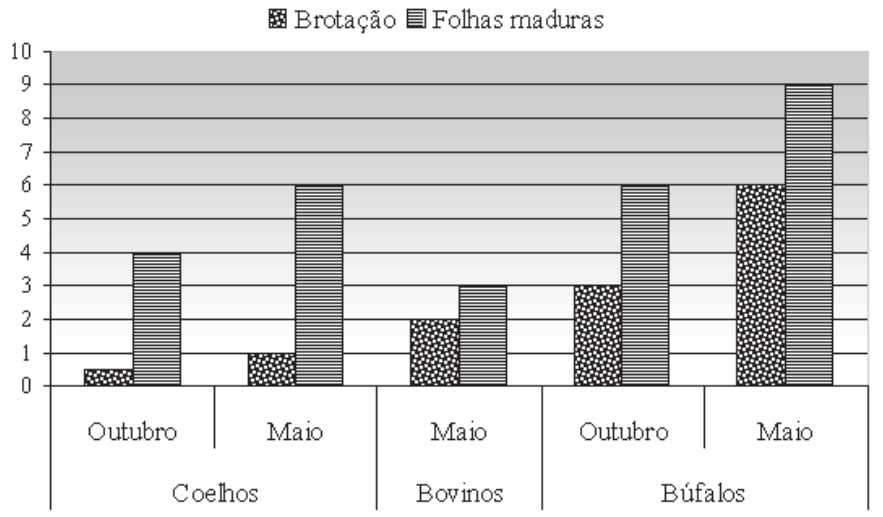

Fig.7. Comparação da sensibilidade dos coelhos com bovinos e búfalos à ação tóxica de Arrabidaea bilabiata. sentou congestão nos Coelhos 1391, 1399, 1417 e 1405 e grupos de fibras cardíacas tumefeitas, com perda da estriação transversal e aumento da eosinofilia nos Coelhos 1397 e 1400 . No pulmão evidenciaram-se congestão nos Coelhos 1391, 1394, 1397, 1400, 1417 e 1405 e edema nos Coelhos 1391 e 1419.

\section{DISCUSSÃO E CONCLUSÃO}

5

Nos experimentos realizados por Tokarnia et al. (2004) e nos do presente estudo, as folhas dessecadas de Arrabidaea bilabiata se revelaram mais tóxicas quando em brotação e quando coletadas em outubro. Enquanto que em relação aos coelhos, a dose letal da brotação coletada em outubro foi de $0,5 \mathrm{~g} / \mathrm{kg}$ e a da folha madura foi de $4,0 \mathrm{~g} / \mathrm{kg}$, a dose letal da brotação coletada em maio foi de $1,0 \mathrm{~g} / \mathrm{kg}$ e da folha madura foi de $6,0 \mathrm{~g} / \mathrm{kg}$. Em outubro, a brotação foi duas vezes mais tóxica que em maio e a folha madura foi uma vez e meia mais tóxica em outubro do que em maio.

Ao compararmos a sensibilidade dos coelhos a dos búfalos à ação tóxica de $A$. bilabiata, verificamos que em ambas as épocas do ano (outubro e maio) a brotação foi seis vezes mais tóxica para os coelhos do que para os búfalos e que as folhas maduras foram 1 vez e meia mais tóxicas. Já os bovinos, foram duas vezes mais resistentes que os coelhos à brotação coletada em maio e duas vezes mais sensíveis que os coelhos às folhas maduras (Fig.7). Verificou-se, portanto, que houve pouca variação com relação à toxidez da A. biabiata entre bovinos e coelhos. Por outro lado, os 
búfalos mostraram-se mais resistentes que os coelhos à ação tóxica de $A$. bilabiata nas duas épocas do ano e com a planta nos dois estados de maturação.

O quadro clínico observado nos coelhos intoxicados por $A$. bilabiata, caracterizado principalmente por "morte súbita", foi bastante uniforme, e semelhante ao verificado anteriormente, nas intoxicações experimentais em coelhos (Döbereiner et al. 1984), bovinos (Döbereiner et al. 1983, Tokarnia et al. 2004) e búfalos (Tokarnia et al. 2004).

Presume-se que o princípio tóxico possa ser responsável pela insuficiência cardíaca aguda nos animais intoxicados, por interferir diretamente no funcionamento cardíaco e posteriormente no desenvolvimento de choque cardiogênico. $O$ ácido monofluoracético torna-se tóxico quando é convertido em fluoracetil-CoA. Este composto reage com o ácido oxaloacético para formar o fluorcitrato e este, por sua vez, inibe a aconitase (Robinson \& Maxie 1993), enzima responsável pela transformação do citrato em cis-aconitase. A aconitase contém um íon $\mathrm{Fe}^{2+}$ em seu centro ativo que se liga irreversivelmente ao átomo $\mathrm{F}$ do fluorocitrato (Krebs et al. 1994). O resultado é o acúmulo de grandes quantidades de citrato nos tecidos, inibição da produção adequada de adenosina trifosfato (ATP), levando à insuficiência do miocárdo (Radostits et al. 2002).

Estes mecanismos patogenéticos propostos acima poderiam justificar as lesões histopatológicas caracterizadas pela presença de congestão e edema pulmonar encontrada nos coelhos de nossos experimentos.

Embora, na maioria dos casos, a evolução tenha variado de 1-3 minutos, o tempo decorrido entre a ingestão da planta e a morte dos animais foi de $2 \mathrm{~h}$ e $51 \mathrm{~min}$ a 16 horas e $3 \mathrm{~min}$. Dessa forma é possível que parte dos animais, já antes da chamada "fase final dramática", estivessem apresentando algum grau de insuficiência cardíaca (pré-choque) que tenha resultado em má oxigenação tecidual com conseqüiente lesão endotelial, coagulação intravascular disseminada (CID) e formação de corpúsculos de choque, encontrados em três coelhos (37,5\% dos casos).

Dos quatro coelhos ( $50 \%$ dos casos) em que foram observadas alterações necróticas no fígado, dois deles apresentaram uma necrose mais intensa (Coelho 1397 e 1419). Observamos que esses animais apresentaram um tempo de sobrevida maior após o início da administração da planta (16h 3min e $10 \mathrm{~h}$ e $2 \mathrm{~min}$ respectivamente). Segundo Peixoto et al (1987), é provável que, nestes casos em que a evolução é mais longa, um quadro final de choque cardiogênico seja o responsável pela morte dos animais.

Cotran et al. (2000) citam que talvez o resultado mais comum da CID aguda seja o choque, devido à redução do retorno venoso ao ventrículo direito e hipertensão arterial sistêmica e pulmonar secundária a trombose. Kitt \& Schulz (1985), relatam que, em coelhos, os órgãos como fígado, rim e coração são os mais freqüentemente afetados em quadros de choque, o que coincide com os órgãos que apresentaram congestão nos coelhos do presente estudo.

A vacuolização hidrópico-vacuolar nas células epiteliais renais encontrada em quatro coelhos ( $50 \%$ dos casos) de nossos experimentos é bastante característica. Peixoto et al. (1987) relatam que, em geral, não há outra causa que possa afetar somente as células epiteliais dos túbulos contornados distais. Certas substâncias tóxicas ao rim e que cursam também com nefrose tubular afetam, sobretudo, os túbulos contornados proximais (Maxie 1993, Jones et al. 2000). As lesões cardíacas degenerativas observadas em $25 \%$ dos casos de nossos experimentos são bastante inespecíficas e podem ser observadas em animais intoxicados por outras plantas e afetados por outras enfermidades que cursam com hipoxemia aguda (Robinson \& Maxie 1993), consequiência comum de uma insuficiência cardíaca de evolução rápida.

Concluímos, portanto, que o estado de maturação e época da coleta são fatores que influenciam na toxidez de Arrabidaea bilabiata, pois a planta mostrou-se mais tóxica quando em brotação e quando coletada na época de seca, confirmando, assim, os dados obtidos nos experimentos realizados com búfalos e bovinos.

Agradecimentos.- Ao Dr. Diomedes Barbosa pela ajuda na obtenção e remessa da planta e ao Sr. João Luís pela colaboração prestada na parte de trituração de Arrabidaea bilabiata.

\section{REFERÊNCIAS}

Costa C.P.R. \& Lima A.E. 1989. Brazilian-Sino Symposium on Chemistry and Pharmacology of Natural Products, Rio de Janeiro.

Cotran R.S., Kumar V. \& Collins T. 2000. Robbins' Patologia Estrutural e Funcional. 6a ed. Editora Guanabara Koogan, Rio de Janeiro.

Döbereiner J., Resende A.M.L \& Tokarnia C.H. 1976. Intoxicação experimental por Baccharis coridifolia em coelhos. Pesq. Agropec. Bras. 11:27-35

Döbereiner J., Tokarnia C.H \& Silva M.F. 1983. Intoxicação por Arrabidaea bilabiata em bovinos na Região Amazônica do Brasil. Pesq. Vet. Bras. 3(1):17-24.

Döbereiner J., Peixoto P.V. \& Tokarnia C.H. 1984. Intoxicação experimental por Arrabidaea bilabiata (Bignoniaceae) em coelhos. Pesq. Vet. Bras. 4(3):8996.

Jones T.C., Hunt R.D. \& King N.W. 2000. Patologia Veterinária. 1a ed. (brasileira). Editora Manole, São Paulo.

Kitt T \& Schulz L.-C. 1985. Tratado de Anatomia General: para Veterinarios y Estudiantes de Veterinária. 2a ed. Editora Labor, Barcelona.

Krebs H.C., Kemmerling W. \& Habermehl G. 1994. Qualitative and quantitative determination of fluoroacetic acid in Arrabidaea bilabiata and Palicourea marcgravii by F-19-NMR Spectroscopy. Toxicon 32 (6):909913.

Maxie M.G. 1993. The urinary system, p.447-538. In: Jubb K.V.F., Kennedy P.C. \& Palmer N. (ed.) Pathology of Domestic Animals. Vol. 2. 4th ed. Academic Press, San Diego.

Oliveira M.M. 1963. Chromatographic isolation of monofluoroacetic acid from Palicourea marcgravii St.Hill. Experientia19:586-587.

Peixoto P.V., Tokarnia C.H., Döbereiner J, Peixoto C.S. 1987. Intoxicação experimental por Palicourea marcgravii (Rubiaceae) em coelhos. Pesq. Vet. Bras. 7(4):117-129.

Poser G.L.von, Schripsema J., Henriques A.T. \& Jensen S.R. 2000. Biochem. Syst. Ecol. 28:351-366.

Robinson W.F. \& Maxie M.G. 1993. The cardiovascular system, p.1-100. In: Jubb K.V.F. \& Kennedy P.C. \& Palmer N. (ed.) Pathology of Domestic Animals. Vol.3. 4th ed. Academic Press, San Diego.

Tokarnia C.H., Barbosa J.D., Oliveira C.M.C., Brito M.F., Oliveira R.B. \& Barbas L.A. 2004. Aspectos epidemiológicos e clínico-patológicos comparados da intoxicação por Arrabidaea bilabiata (Bignoniaceae) em búfalos e bovinos. Pesq. Vet. Bras. 24(2):74-79.

Tokarnia C.H., Döbereiner J. \& Peixoto P.V. 2000. Plantas Tóxicas do Brasil. Editora Helianthus, Rio de Janeiro. 